\title{
Nurse perspectives on the implementation of routine telemonitoring for high-risk diabetes patients in a primary care setting
}

\author{
Bonnie M. Vest ${ }^{1}$, Victoria M. Hall ${ }^{1}$, Linda S. Kahn ${ }^{1}$, Arvela R. Heider ${ }^{2}$, Nancy Maloney ${ }^{3}$ and Ranjit Singh ${ }^{1}$ \\ ${ }^{1}$ Department of Family Medicine, University at Buffalo, Buffalo, NY, USA \\ ${ }^{2}$ Canisius College, Buffalo, NY, USA \\ ${ }^{3}$ HealtheLink $^{\mathrm{TM}}$, Buffalo, NY, USA
}

\begin{abstract}
Aims: The purpose of this qualitative evaluation was to explore the experience of implementing routine telemonitoring (TM) in real-world primary care settings from the perspective of those delivering the intervention; namely the TM staff, and report on lessons learned that could inform future projects of this type. Background: Routine TM for high-risk patients within primary care practices may help improve chronic disease control and reduce complications, including unnecessary hospital admissions. However, little is known about how to integrate routine TM in busy primary care practices. A TM pilot for diabetic patients was attempted in six primary care practices as part of the Beacon Community in Western New York. Methods: Semi-structured interviews were conducted with representatives of three TM agencies $(n=8)$ participating in the pilot. Interviews were conducted over the phone or in person and lasted $\sim 30 \mathrm{~min}$. Interviews were audio-taped and transcribed. Analysis was conducted using immersion-crystallization to identify themes. Findings: TM staff revealed several themes related to the experience of delivering TM in real-world primary care: (1) the nurse-patient relationship is central to a successful TM experience, (2) TM is a useful tool for understanding socio-economic context and its impact on patients' health, (3) TM staff anecdotally report important potential impacts on patient health, and (4) integrating TM into primary care practices needs to be planned carefully. Conclusions: This qualitative study identified challenges and unexpected benefits that might inform future efforts. Communication and integration between the TM agency and the practice, including the designation of a point person within the office to coordinate TM and help address the broader contextual needs of patients, are important considerations for future implementation. The role of the TM nurse in developing trust with patients and uncovering the social and economic context within which patients manage their diabetes was an unexpected benefit.
\end{abstract}

Key words: development; diabetes mellitus; evaluation; primary healthcare; telemedicine

Received 23 September 2015; revised 8 February 2016; accepted 14 May 2016;

first published online 8 June 2016

\section{Introduction}

Telemonitoring (TM) has been widely used in the United States, Europe, and parts of Asia to

Correspondence to: Bonnie M. Vest, PhD, Department of Family Medicine, 77 Goodell Street, Suite 220, Buffalo, NY 14203, USA. Email: bvest@buffalo.edu improve monitoring and care for a wide variety of medical conditions (Meystre, 2005; Pare et al., 2007; Bashshur et al., 2014), in particular cardiopulmonary diseases, such as congestive heart failure and chronic obstructive pulmonary disease (Meystre, 2005) and other chronic diseases, such as diabetes (Bashshur et al., 2014). In addition to studying the clinical effectiveness of TM for improving disease-specific

(C) Cambridge University Press 2016 
indicators, TM has also been examined from an economic standpoint as a cost-effective initiative to improve access and quality of care for patients with chronic disease (Bashshur et al., 2014) and help prevent hospitalizations among high-risk patients (Cherry et al., 2002; Jaana and Pare, 2007; Pare et al., 2007; Polisena et al., 2009b; Bashshur et al., 2014). A recent review cited several studies, conducted across a wide range of international settings, demonstrating the effectiveness of TM interventions for improving chronic disease management and reducing service use, mostly within the context of highly controlled randomized controlled trials (Bashshur et al., 2014).

Diabetes is a global health problem, affecting millions of patients in countries around the world. In the United States, diabetes affects nearly 26 million people and is responsible for $\$ 174$ billion in healthcare costs each year (C.F.D.C.A Prevention (Centers for Disease Control and Prevention), 2011). A total of 511407 diabetes-related preventable hospitalizations were reported in 2006, an increase of $18 \%$ since 1998 (Wang et al., 2009). Of these hospitalizations, $36 \%$ were caused by shortterm complications and uncontrolled diabetes (Wang et al., 2009). Better outpatient management of diabetes in primary care settings could help prevent many of these hospitalizations (DagogoJack, 2002; Greisinger et al., 2004).

Research on TM effectiveness specifically for diabetes has demonstrated mixed results (Farmer et al., 2005; Pare et al., 2007; Costa et al., 2009). Some studies report little to no effect on glycemic control or hospitalization rates (Farmer et al., 2005; Costa et al., 2009; Lin et al., 2012; Takahashi et al., 2012; Wakefield et al., 2014). Others report that tele-health interventions are effective for improving glycemic control, patient education, reducing hospitalization rates among diabetic patients (Cherry et al., 2002; Gomez et al., 2002; Chase et al., 2003; Jaana and Pare, 2007; Pare et al., 2007; Polisena et al., 2009b; Weinstock et al., 2011; Stone et al., 2012) and potentially reducing cost (Cherry et al., 2002; Chase et al., 2003).

TM has been proposed as a method to enhance primary care provision by filling patient information gaps between clinic visits and alerting clinicians to potential problems (Davis et al., 2014; Koopman et al., 2014; Wakefield et al., 2014). Implementing TM into routine primary care (ie, outside of the context of a controlled experimental trial) must be carefully considered, due to increased practice staff workload, concerns over data integration and clinical relevance, and, in the US context, limited reimbursement from insurance companies for care provided between office visits (Davis et al., 2014; Koopman et al., 2014; Wakefield et al., 2014).

In 2010, Western New York was selected as one of 17 Beacon Communities nationwide by the United States Office of the National Coordinator for Health Information Technology. The Beacon Community Cooperative Agreement Program provided funding for three years to enable these communities to build and expand on regional health information technology (IT) infrastructure and demonstrate how health IT could advance patientcentered care, while achieving better health, better care, at lower cost (Ricciardi et al., 2013; Des Jardins et al., 2015). As part of this regional quality improvement initiative, a community organization implemented a TM pilot program with three homecare agencies to target primary care diabetic patients deemed to be at high-risk of hospitalization. The project was intended to provide monitoring and day-to-day management of high-risk patients in order to identify problems and intervene in the primary care setting, before patients presented to the emergency room or hospital.

The purpose of this qualitative evaluation study was to explore the experience of implementing routine TM in busy primary care settings from the perspective of those delivering the intervention; namely the TM staff, and report on lessons learned that can inform future projects of this type.

\section{Program description}

In this community project, the routine TM model was implemented with three homecare agencies and six primary care practices. The overall goal of the TM program was to demonstrate the effectiveness of TM as part of routine primary care for preventing hospitalizations among high-risk patients in real-world settings. In the context of the privatized US healthcare setting, this meant engaging with three different homecare agencies with slightly different equipment and procedures and a variety of practice settings. Each homecare agency provided patients with equipment (differed by agency; see Table 2) and educated patients on how to test themselves daily for weight, blood pressure and glucose. The TM agencies received patient 
readings on a daily basis; nurses reviewed the patient data and responded to any numbers that were outside of predetermined limits (set in collaboration with the patients' provider), by calling the patient and/or the provider. In addition to TM, glucometers and test strips were provided for some patients with financial difficulties. The six primary care practices enrolled in the pilot identified diabetic patients (Type I or Type II, regardless of insulin use) meeting the following criteria: (1) between the ages of 18 and 75; (2) have congestive heart failure or chronic kidney disease in addition to diabetes and at risk (as determined by each practice) for hospitalization or re-hospitalization; (3) signed a consent to have data shared electronically; (4) expressed desire to participate in a TM program and follow TM guidelines; and (5) deemed likely that TM will improve care and patient outcomes, based on physician assessment. While practices were asked to enroll patients using these criteria, in this real-world implementation pilot, practices developed their own systems for identifying eligible patients and physician judgment was used to determine whether diabetes was uncontrolled or whether the patient was at risk for hospitalization. Specific parameters in terms of type of diabetes and hemoglobin A1c levels were left flexible, and each practice used different criteria for enrolling patients. Between May 2011 and August 2013, 144 patients were enrolled across the six participating primary care providers (PCPs) and 99 patients remained in the program for at least six months.

\section{Evaluation methods}

Qualitative interviews were conducted with staff from the TM vendors (nurses and administrators) to identify key factors affecting the implementation of TM in the primary care practices and the experience of day-to-day TM.

\section{Data collection}

Between February and June of 2013, semistructured qualitative interviews were conducted with nurses and administrators from the three TM agencies participating in the pilot. The same set of questions was used for both nurses and administrators, and in some cases they were interviewed jointly (Table 1). TM staff were asked about their experiences with the Beacon TM pilot including, their daily roles and activities, the nature of their interactions with patients and providers, and their thoughts on using TM to prevent hospitalizations. These participants were chosen to gain insight into the interface between the TM agency and the primary care practices, from the perspective of the agencies providing the intervention. Interviews were conducted by a medical anthropologist (BMV) over the phone or in person and lasted $\sim 30$ min. Interviews were audio-taped and transcribed. The study protocol was approved by the Social and Behavioral Sciences Institutional Review Board at the [University at Buffalo]. All participants provided informed consent to participate in the interviews; written consent was used for in-person interviews and verbal consent with the provision of a study information sheet was used for telephone interviews. Participants received a \$20 gift card as a thank you for their participation.

\section{Data analysis}

Two researchers (a medical anthropologist (BMV) and an RN/MPH (VMH)) independently reviewed the transcripts and identified themes. Analysis was conducted by means of immersioncrystallization (Borkan, 1999), an iterative process of data analysis whereby the researchers immerse themselves repeatedly in the data to identify emerging themes. Analysis was content-driven, allowing the data to 'speak' for itself without being guided by a theoretical model. Themes were identified based upon repeated ideas that emerged across interviews. After independent review, the researchers met to compare identified themes and resolve any discrepancies. Because the interview questions were the same, the nurse and administrator transcripts were analyzed as a collective, and the themes cut across both participant groups. While a small sample, the eight interviews represent all TM agency staff engaged in this implementation pilot, and therefore, all experiences and perspectives were captured in the analysis. Data analysis was based upon all individuals participating in the pilot, rather than on theoretical saturation. Nonetheless, analysis of the transcripts revealed remarkably consistent responses, perceptions and experiences across all participants, indicating probable saturation.

Primary Health Care Research \& Development 2017; 18: 3-13 
Table 1 Telemonitoring (TM) staff interview questions

1. How long have you worked as a telemonitoring nurse?

a. What is your background, degree?

2. What do you know about the Beacon telemonitoring program?

3. Describe your process for utilizing the Beacon telemonitoring data and responding to alerts from the system.

4. What types of contact or interactions do you have with the patients?

a. How often are you in contact with the patients?

b. How long does this contact usually last?

5 . What is the most common trigger for contact with your patients?

a. How do you handle these situations? Which steps do you take?

6. Do you provide patient education?

7. Which types of patient education do you provide to the patients?

a. How often do you do patient education?

b. Are you sending anything back to the patients?

8. How often are you in contact with the patients' practice?

a. Who is your main contact?

b. What most commonly triggers this contact?

9. What are your perceptions of the patient experience with the Beacon telemonitoring?

10. What are your perceptions of the practices' experience with the Beacon telemonitoring program?

a. What differences do you see between the practices you work with on the Beacon program?

b. What differences do you see between this telemonitoring program and other telemonitoring programs?

11. How effective do you feel the Beacon telemonitoring is for patients?

a. Examples of improved cases?

12. Do you believe that the preventive telemonitoring has helped reduce hospital admissions?

13. Do you believe that preventive telemonitoring has improved patients' health overall?

a. Could you provide examples?

14. What suggestions do you have for improving the Beacon telemonitoring program?

15. Is there anything else about your experiences with Beacon you would like to share with us that we haven't already talked about?

\section{Results}

Interviews were conducted with eight staff from the TM agencies; five TM nurses and three agency administrators. One administrator and at least one nurse from each of the three agencies were interviewed. TM nurses were responsible for working with the patients each day. The administrator from each agency was responsible for overseeing all TM, including the set-up and coordination of the Beacon TM program within their agency. All of the administrators had previously worked as nurses in direct patient care and in TM before shifting into an administrative position at their respective agencies. All of the nurses had some experience working in the TM field (range 2-12 years) and had worked several years in other areas of healthcare before beginning work with TM. These TM nurses were not dedicated solely to the Beacon project, and were simultaneously assigned to other patients within their organization. Each agency reported $\sim 25-50$ patients enrolled in the Beacon TM program, but were monitoring hundreds of patients across multiple programs daily.
From the perspective of the TM staff, they conducted the same daily procedures and activities related to the Beacon patients as for other TM patients (see description below). TM staff described the main difference between the Beacon TM and other TM programs as the emphasis on diabetes, and the length of time patients were on the TM program (up to two years as compared with 60-90 days of TM that would normally be covered under other programs).

The interviews revealed variation in the TM intervention provided by each of the agencies. The TM agencies varied in their approach to providing TM services, such as: the equipment used with patients, the amount of patient education provided by the TM device, the process for setting the patient up with TM, and the protocols for when and how to contact patients and providers (Table 2).

Although considerable variation existed in the TM modality used by the three agencies, there was an overarching consistency among the TM agencies in how they conducted their daily TM responsibilities. Patients tested blood sugar, 
Table 2 Variation across telemonitoring agencies (information based on interview responses from participants)

\begin{tabular}{|c|c|c|c|c|c|c|c|c|c|c|}
\hline $\begin{array}{l}\text { TM } \\
\text { agency }\end{array}$ & TM system & Other equipment & No. of nurses & $\begin{array}{l}\text { No. of } \\
\text { patients (at } \\
\text { most on } \\
\text { Beacon) }\end{array}$ & $\begin{array}{l}\text { Patient education } \\
\text { through TM } \\
\text { device }\end{array}$ & $\begin{array}{l}\text { TM device } \\
\text { asks health } \\
\text { symptoms }\end{array}$ & $\begin{array}{l}\text { Initial set up/ } \\
\text { face to face } \\
\text { with patient }\end{array}$ & Patient contact & Physician contact & If no testing \\
\hline $\mathrm{T} 1$ & $\begin{array}{l}\text { Health Buddy by } \\
\text { McKesson } \\
\text { Wired and some } \\
\text { wireless option }\end{array}$ & None provided & $\begin{array}{l}\text { Two nurses } \\
\text { (share all patients) }\end{array}$ & $\sim 22$ & $\begin{array}{l}\text { Education specific } \\
\text { to disease }\end{array}$ & $\begin{array}{l}\text { Daily health/ } \\
\text { symptoms }\end{array}$ & $\begin{array}{l}\text { Separate } \\
\text { installer sets } \\
\text { up equipment }\end{array}$ & $\begin{array}{l}\text { Only contacts } \\
\text { patients if alert }\end{array}$ & $\begin{array}{l}\text { Only if there is a } \\
\text { problem }\end{array}$ & $\begin{array}{l}\text { Call patient that } \\
\text { day if no test, after } \\
\text { two days of no } \\
\text { testing notify } \\
\text { doctor and patient } \\
\text { every day }\end{array}$ \\
\hline T2 & $\begin{array}{l}\text { Android-based } \\
\text { Smart phone/ } \\
\text { bluetooth system }\end{array}$ & $\begin{array}{l}\text { Patients provided } \\
\text { with glucometer } \\
\text { and initial supply } \\
\text { of test strips }\end{array}$ & One nurse & 49 & $\begin{array}{l}\text { No education } \\
\text { through TM } \\
\text { device }\end{array}$ & None & $\begin{array}{l}\text { TM nurse does } \\
\text { all installation } \\
\text { and meets } \\
\text { patients face } \\
\text { to face in their } \\
\text { home }\end{array}$ & $\begin{array}{l}\text { Tries to maintain } \\
\text { weekly contact } \\
\text { with all patients, } \\
\text { even if normal } \\
\text { results }\end{array}$ & $\begin{array}{l}\text { As needed for } \\
\text { problems, send } \\
\text { reports on all } \\
\text { patients at } \\
\text { intervals }\end{array}$ & $\begin{array}{l}\text { Call patient after } \\
\text { one day of non- } \\
\text { use }\end{array}$ \\
\hline T3 & $\begin{array}{l}\text { Cardio Com } \\
\text { Wired (must plug } \\
\text { into unit once/day) }\end{array}$ & Unknown & $\begin{array}{l}\text { Two nurses (each } \\
\text { assigned one } \\
\text { practice and its } \\
\text { patients) }\end{array}$ & $\sim 45$ & $\begin{array}{l}\text { Limited education } \\
\text { for first } 60 \text { days, } \\
\text { then 'drops off' }\end{array}$ & $\begin{array}{l}\text { Daily health/ } \\
\text { symptoms }\end{array}$ & $\begin{array}{l}\text { Separate } \\
\text { nurse sets up } \\
\text { equipment, } \\
\text { one nurse } \\
\text { reported } \\
\text { meeting all } \\
\text { patients at the } \\
\text { practice } \\
\text { before TM }\end{array}$ & $\begin{array}{l}\text { Only contacts } \\
\text { patients if alert }\end{array}$ & $\begin{array}{l}\text { As needed for } \\
\text { problems, send } \\
\text { reports on all } \\
\text { patients at } \\
\text { intervals }\end{array}$ & $\begin{array}{l}\text { Don't necessarily } \\
\text { call if just miss } \\
\text { one day - call after } \\
\text { three days of non- } \\
\text { use }\end{array}$ \\
\hline
\end{tabular}


weight, and blood pressure daily, and sent these results to the agency. If any of these measures were outside of predetermined parameters established by the patients' doctors, the first course of action by all nurses was to contact the patient to assess the situation. The patients' physicians were notified after this point, though the mechanisms and timing of the notification varied depending on TM agency policy, practice preferences, and the patient situation. Nurses would generally fax an update to physicians if the problem was resolved, or call if a more immediate response was needed.

Analysis of the interview transcripts identified four themes: (1) the nurse-patient relationship is central to a successful TM experience, (2) TM is a useful tool for understanding and addressing patient context, (3) TM staff anecdotally report important potential impacts of TM on patient health, and (4) integrating TM into primary care practices needs to be planned carefully. Each theme is described in the text; exemplary quotations and additional details are provided in Table 3.

\section{The nurse-patient relationship is central to a successful TM experience}

The TM nurse-patient relationship was a predominant theme, highlighted as important to three areas of the TM program; (1) patient education, (2) generating trust, and (3) providing patients with a sense of security.

\section{Patient education}

TM staff cited patient education as a significant portion of their role. This education was provided in several different formats. Two of the three agencies used TM systems that delivered diseasespecific education through the device itself, in the form of generalized daily 'quiz' questions about diabetes self-management. All of the agencies provided patients with educational materials. TM staff reported providing verbal education individualized to each patient's needs throughout each encounter and indicated that the form of education evolved over the course of the project, from more intense education at the beginning, to 'refreshers' as the project progressed and patients became more familiar with their disease and its management.

Primary Health Care Research \& Development 2017; 18: 3-13

\section{Generating trust}

TM staff described excellent rapport with patients over the phone, as they built trust and learned about their patients. The continuity in the relationship was important in finding out what was really happening in patients' lives. Trust enabled the TM staff to uncover social and economic factors affecting patients' test results.

\section{Providing a sense of security}

TM staff explained that patients appreciated the relationship; the sense that someone cares and 'has their back.' Compliance was facilitated by the reassuring feeling that someone cared about them and their health.

\section{TM is a useful tool for understanding and addressing patient context}

TM staff noted that they were involved in the full context of patients' lives, assisting with a wide range of social, financial, and non-diabetes-related health concerns affecting patients' ability to manage their diabetes. For example, contact prompted by reviewing patients' TM data led to TM staff learning about contextual factors that impacted patients' ability to manage their diabetes, such as difficulties with insurance coverage for certain medications or testing supplies and financial difficulties related to low-income status, such as eating poorer quality foods at the end of the month when resources were low. As one staff member said, TM 'opens the door' to a whole range of other issues that impact patients' health.

\section{TM staff anecdotally report important potential impacts of TM on patient health}

TM staff reported improvements they observed in patients who adhered to TM, including: losing or maintaining their weight, decreases in $\mathrm{HbA} 1 \mathrm{c}$, and increased discipline. TM enabled staff to comprehensively address patients' health needs beyond diabetes, such as discovering undiagnosed hypertension and providing wound care.

In addition, they were able to expedite care for urgent health needs while avoiding unnecessary office visits. Although they had no quantitative data to substantiate this, TM staff reported an impression that TM was effective for preventing hospitalizations and emergency department visits, because 
Table 3 Telemonitoring (TM) Staff identified lessons learned and example quotations

\begin{tabular}{lll}
\hline Theme & Sub-theme & Quotation \\
\hline $\begin{array}{ll}\text { Nurse-patient relationship central } \\
\text { to successful TM }\end{array}$ & $\begin{array}{l}\text { Patient } \\
\text { education }\end{array}$ & $\begin{array}{l}\text { When we talk with them, we're always in how-can-l-help-you-to-learn mode } \\
\text { and help them to know how to best handle their process, their disease } \\
\text { process... They might have questions on their new insulin, 'the doctor put me } \\
\text { on this, is it long-acting, is it short-acting. They went so fast in the office I didn't } \\
\text { get it...' (Participant T1-2 }\end{array}$
\end{tabular}

Generating ...they'll tell you that they just had a cheeseburger, a small fry and a diet pop trust when they really had a whopper, a large fry, an apple pie and a regular pop and you just build up the rapport with them. You have to tell them, 'well that wouldn't make your blood sugar real high so what else did you have?' 'Oh well I'm lying' and then come out and tell you the truth. Great rapport over the phone with many of them. (Participant T3-2)

Or they run out of their money, so for five, six days they don't have any medications... That's sad and it takes a while before they will admit to you that, that's a problem for them... You have to be very careful how you speak to them and eventually they trust you and say, 'yeah, I don't have the money.' (Participant T2-2)

Providing a I think that when clients feel that they're being cared for, somebody cares sense of about them... their compliance with their medication and their... diet is security enhanced. (Participant T2-1)

TM useful for understanding and addressing patient context
We have lots of people who have challenges just because of their insurances and different things happen in their lives; they lose their job, ... you see their blood glucoses increase and then you see that they're not taking their insulin, 'well, it's the beginning of the year, I can't afford my insulin.' .... We have depression, the nurses will give you examples of things like that, crisis, we had to call Crisis Services because of depression. (Participant T3-1)

I have a patient that weighs over 400 pounds... [He] developed bilateral leg ulcers. With the help of some supervisors here at the [agency] and the provider he was affiliated with, we were able to get him out-patient wound care and insulin through charity care of the companies that manufactured the insulin.... The wounds all healed up in about a year's time... he never was hospitalized and he did phenomenal. His hemoglobin $\mathrm{A} 1 \mathrm{C}$ went from being above average to right at normal, although his weight didn't change... (Participant T3-3)

Say for instance, a patient has a small blister on their foot and it hurts and it bothers them, but they have an appointment two weeks from that time. Most patients in my experience, will wait for their appointment... Where now these things come up and... I say, 'do you truly have a wound?' and if they say yes, I explain to them how advocating for themselves right now is so beneficial to them as opposed for waiting two weeks... and making the problem bigger. (Participant T3-3)

I think in the beginning they really thought, 'holy cow, these reports are a lot and I can't believe we got ourselves into this.' And the phone calls that we made in the beginning and getting everybody set up... was a little much.... It takes probably four months to get things from infancy to where you're all comfortable. (Participant T3-2)

I think both practices like having their clients being looked after. We have a better communication with one office than we do the other. P1 has a certified Diabetic educator on board and that obviously has been a big plus for this type of a grant when you're working with diabetics. We have access to her immediately. Sometimes with P2, we don't have the same type of response although I do believe that the physicians and the clients both enjoy being on the program. But we've had good response from both offices, different types of responses. (Participant T2-1)

\footnotetext{
${ }^{a}$ Participant numbers refer to the TM Agency $(\mathrm{T} 1, \mathrm{~T} 2$, or $\mathrm{T} 3)$ and the Participant no. $(1,2$, or 3$)$ from that agency.
} 
they were able to identify and arrange for treatment of health issues, such as those mentioned above.

\section{Integrating TM into primary care practices needs to be planned carefully}

TM staff reported a variety of elements affecting the integration of TM into primary care. Communication varied based on practice preferences. The frequency of reporting, the content of reports, and transmittal of reports (phone, fax, etc.) varied by practice. In most cases, the practice had identified a care coordinator or certified diabetes educator as the primary contact for the TM agencies. TM staff reported positive relationships with these individuals, and noted that communication was more difficult in practices without an identified point person. Project intensity for the practices varied over the course of the pilot. TM staff identified several factors at the practice level which they felt impacted the practice experience with TM, including: difficulties with designating staff to coordinate the program, implementing office workflows designed to optimize the use of TM while limiting extra work, and the level of physician buy-in and engagement - which they felt impacted patient engagement. TM staff stressed the importance of selecting appropriate patients for a TM program; based on their experience they reported that patients with uncontrolled diabetes and who were willing to use TM made the best candidates for the program. They also suggested that there should be physician incentives to use the TM data, and ease of use, such as a one-click, visual and easy to read format. Finally, in terms of communication, TM staff would have appreciated more information from the providers regarding care the patient received outside of the TM, such as lab results, medication changes, and appointment results.

\section{Lessons learned}

A TM program is one method by which PCPs can more closely monitor high-risk patients and collaborate with TM staff to identify key factors affecting patient health outcomes. Even though we had a small sample, our study uncovered many findings that confirm and add to previous studies, conducted both in the United States and internationally, on this topic (Davis et al., 2014; Koopman et al., 2014; Wakefield et al., 2014). Our findings strengthen previous work by corroborating their findings from a previously unrepresented perspective, that of the TM staff. Identified themes illustrate important challenges and unexpected benefits of the TM pilot which translate into lessons learned for future projects of this type.

First, TM should focus on the nurse-patient relationship. Our findings underscore the importance of the nurse role in uncovering social determinants of health and acting as a support to patients. Kahn et al. observed this extension of the TM nurse in providing social support and addressing patients' needs to improve health outcomes (Kahn et al., 2009). Our study builds on these findings by examining the role of the TM nurse in developing trust with patients and uncovering the social and economic context within which patients manage their diabetes. This was an unexpected benefit of the TM in this pilot, and one that may be critical to improving patient outcomes. Due to their daily involvement and understanding of patients' situations, TM staff can identify issues crucial to patient health that may be missed in the context of widely spaced office visits. Having a TM nurse who can fulfill this role complements and enhances the care provided in a primary care setting. Providing resources to help TM agencies and practices address the socio-cultural determinants of health uncovered during TM is an important consideration for future projects.

Furthermore, the TM staff in this study repeatedly emphasized additional non-clinical benefits to the patients, such as their appreciation for knowing that someone was monitoring their health. This supports other studies, which have documented the benefits of TM for the patient in terms of mental well-being and security as important, albeit non-quantifiable, positive effects of this type of intervention (Jaana and Pare, 2007; Kahn et al., 2009; Johnston and Weatherburn, 2010; Pols, 2010; Pecina et al., 2011; Fairbrother et al., 2012), which are important considerations in an effort to provide patient-centered care. Further study is needed to determine if TM is the most effective way to provide this type of contact, or if other interventions, such as community health workers and peer models, might provide similar results. One possible advantage of the TM model might be the integration of this support with clinical information. 
Similar to what has been reported in other studies (Jaana and Pare, 2007; Fairbrother et al., 2012; Davis et al., 2014; Koopman et al., 2014), TM staff reported challenges encountered in the integration of TM into the routine workflow of real-world primary care offices, particularly around communication and coordination. From the perspective of the TM staff delivering the intervention, increased communication and integration between the TM agency and the practice are important - especially designating a point person within the office to coordinate TM and address patients' needs. However, TM staff indicated awareness that providing time for such functions remains a challenge for primary care practices in implementing this model. Some studies have reported that TM programs increase provider time for reviewing and responding to additional patient data (Jaana and Pare, 2007) and may also trigger more office visits (Polisena et al., 2009a). Other studies have reported that TM systems that are not integrated with the electronic medical records create extra work, and that information flows and practice staff workflows need to be carefully thought out and defined (Fairbrother et al., 2012; Davis et al., 2014; Koopman et al., 2014). Successful office integration of TM was enhanced by designated care coordinators who viewed TM care as part of their role (Koopman et al., 2014). Our results support these findings and indicate that practices and TM agencies should work together to establish workflows that maximize the potential use of TM data while being mindful of provider time and efficiency.

Finally, TM staff in our study emphasized both disease control and patient buy-in and willingness to use the TM technology as key factors to consider in regards to how patients are identified for the program. Koopman et al. come to a similar conclusion, recommending that patients who were changing their regimen, were newly diagnosed or were uncontrolled - yet are motivated to make a change - may experience greater benefit from a TM program (Koopman et al., 2014).

\section{Limitations}

The qualitative data presented here were collected from a small sample of respondents participating in one pilot program. However, many of the findings support what has already been reported in the literature, corroborating their importance from the perspective of a different TM user group. Reports of improved patient outcomes as a result of the TM are anecdotal and may be subject to bias. Demonstrating improved outcomes was beyond the scope of this qualitative study. Rather, the goal of the qualitative evaluation was to understand the experiences and lessons learned from implementing TM into primary care practices from the perspective of the TM staff.

Another limitation is the absence of perspectives from the other parties (patients and PCPs) participating in the TM pilot. This may have resulted in a partial understanding of the overall experience of the TM program, providing the perspective of only one set of users. However, the findings from this study complement those conducted in other studies with other TM user groups (Davis et al., 2014). We attempted to include staff from the PCP offices but were unable to identify a cohort of individuals across all participating practices that had consistently worked with the TM program for long enough to provide an informed and meaningful perspective and thematic analysis was fragmented. Additionally, consent agreements signed with the patients precluded evaluators from contacting patients enrolled in the pilot for their perspective. Hence we limited this study to the TM staff delivering the service to the patients. While a small sample, the eight individuals interviewed represent $100 \%$ of participating TM staff, so we believe that all experiences and perspectives were adequately represented.

The wide variation in TM implementation within the pilot is another limitation. It is not possible to determine the effects of this variation on the experience of the TM or the perceptions of interviewed TM staff. However, this variation is indicative of the real-world primary care landscape and likely circumstances surrounding the implementation of TM, which makes these findings potentially useful for a wide range of settings, both in the United States and internationally.

\section{Conclusion}

This qualitative exploration of the implementation of telemonitoring for high-risk diabetic patients in US primary care settings revealed several lessons learned. Telemonitoring may offer benefits for the

Primary Health Care Research \& Development 2017; 18: 3-13 
preventive monitoring of at-risk patients in the primary care setting. However, its implementation into the real-world setting of primary care practices needs to be planned carefully in order to maximize the benefits of TM and minimize additional burden on practices. TM staff are positioned to play a key role in the primary care management of high-risk patients by providing timely information about changes in patient health and by identifying contextual factors that impact patient self-management, contributing to more holistic patient-centered care.

\section{Acknowledgments}

This project was funded by the Office of the National Coordinator for Health Information Technology (BEACON Award no. 90BC0003/01).

\section{Conflicts of Interest}

None.

\section{References}

Bashshur, R.L., Shannon, G.W., Smith, B.R., Alverson, D.C., Antoniotti, N., Barsan, W.G., Bashshur, N., Brown, E.M., Coye, M.J., Doarn, C.R., Ferguson, S., Grigsby, J., Krupinski, E.A., Kvedar, J.C., Linkous, J., Merrell, R.C., Nesbitt, T., Poropatich, R., Rheuban, K.S., Sanders, J.H., Watson, A.R., Weinstein, R.S. and Yellowlees, P. 2014: The empirical foundations of telemedicine interventions for chronic disease management. Telemedicine Journal and E-Health 20, 769-800.

Borkan, J. 1999: Immersion/crystallization. In Crabtree, B.F. and Miller, W.L., editors Doing qualitative research, second edition. Thousand Oaks: Sage Publications Inc.

Centers for Disease Control and Prevention. 2011. National diabetes fact sheet: national estimates and general information on diabetes and prediabetes in the United States, 2011. Atlanta, GA: U.S. Department of Health and Human Services Centers for Disease Control and Prevention.

Chase, H.P., Pearson, J.A., Wightman, C., Roberts, M.D., Oderberg, A.D. and Garg, S.K. 2003: Modem transmission of glucose values reduces the costs and need for clinic visits. Diabetes Care 26, 1475-479.

Cherry, J.C., Moffatt, T.P., Rodriguez, C. and Dryden, K. 2002: Diabetes disease management program for an indigent population empowered by telemedicine technology. Diabetes Technology \& Therapeutics 4, 783-91.

Costa, B.M., Fitzgerald, K.J., Jones, K.M. and Dunning, Am, T. 2009: Effectiveness of IT-based diabetes management interventions: a review of the literature. BMC Family Practice 10, 72.

Primary Health Care Research \& Development 2017; 18: 3-13
Dagogo-Jack, S. 2002: Preventing diabetes-related morbidity and mortality in the primary care setting. Journal of the National Medical Association 94, 549-60.

Davis, M.M., Freeman, M., Kaye, J., Vuckovic, N. and Buckley, D.I. 2014: A systematic review of clinician and staff views on the acceptability of incorporating remote monitoring technology into primary care. Telemedicine Journal and E-Health 20, 428-38.

Des Jardins, T., Drone, S.A., Hashisaka, S., Hazzard, J., Hunt, S.B., Massey, K., Rein, A., Schachter, A. and Turske, S. 2015: Patient engagement and activation in three underserved Beacon communities. Journal of Health Care for the Poor \& Underserved 26, 777-83.

Fairbrother, P., Pinnock, H., Hanley, J., Mccloughan, L., Sheikh, A., Pagliari, C., Mckinstry, B. and Team, T.P. 2012: Continuity, but at what cost? The impact of telemonitoring COPD on continuities of care: a qualitative study. Primary Care Respiratory Journal 21, 322-28.

Farmer, A., Gibson, O.J., Tarassenko, L. and Neil, A. 2005: A systematic review of telemedicine interventions to support blood glucose self-monitoring in diabetes. Diabetes Medicine 22, 1372-378.

Gomez, E.J., Hernando, M.E., Garcia, A., Del Pozo, F., Cermeno, J., Corcoy, R., Brugues, E. and De Leiva, A. 2002: Telemedicine as a tool for intensive management of diabetes: the DIABTel experience. Computer Methods and Programs in Biomedicine 69, 163-77.

Greisinger, A.J., Balkrishnan, R., Shenolikar, R.A., Wehmanen, O.A., Muhammad, S. and Champion, P.K. 2004: Diabetes care management participation in a primary care setting and subsequent hospitalization risk. Disease Management 7, 325-32.

Jaana, M. and Pare, G. 2007: Home telemonitoring of patients with diabetes: a systematic assessment of observed effects. Journal of Evaluation in Clinical Practice 13, 242-53.

Johnston, G. and Weatherburn, G. 2010: Automated weight monitoring in chronic heart failure: the excluded majority. Journal of Telemedicine \& Telecare 16, 190-92.

Kahn, L.S., Fox, C.H., Carrington, J., Desai, U., Bartlett, D.P., Lyle, H. and Kowalski, M. 2009: Telephonic nurse case management for patients with diabetes and mental illnesses: a qualitative perspective. Chronic Illness 5, 257-67.

Koopman, R.J., Wakefield, B.J., Johanning, J.L., Keplinger, L.E., Kruse, R.L., Bomar, M., Bernt, B., Wakefield, D.S. and Mehr, D.R. 2014: Implementing home blood glucose and blood pressure telemonitoring in primary care practices for patients with diabetes: lessons learned. Telemedicine Journal and E-Health 20, 253-60.

Lin, W.C., Chien, H.L., Willis, G., O'connell, E., Rennie, K.S., Bottella, H.M. and Ferris, T.G. 2012: The effect of a telephone-based health coaching disease management program on Medicaid members with chronic conditions. Medical Care 50, 91-98.

Meystre, S. 2005: The current state of telemonitoring: a comment on the literature. Telemedicine Journal and E-Health 11, 63-69. 
Pare, G., Jaana, M. and Sicotte, C. 2007: Systematic review of home telemonitoring for chronic diseases: the evidence base. Journal of the American Medical Informatics Association 14, 269-77.

Pecina, J.L., Vickers, K.S., Finnie, D.M., Hathaway, J.C., Hanson, G.J. and Takahashi, P.Y. 2011: Telemonitoring increases patient awareness of health and prompts healthrelated action: initial evaluation of the TELE-ERA study. Telemedicine Journal and E-Health 17, 461-66.

Polisena, J., Coyle, D., Coyle, K. and Mcgill, S. 2009a: Home telehealth for chronic disease management: a systematic review and an analysis of economic evaluations. International Journal of Technology Assessment in Health Care 25, 339-49.

Polisena, J., Tran, K., Cimon, K., Hutton, B., Mcgill, S. and Palmer, K. 2009b: Home telehealth for diabetes management: a systematic review and meta-analysis. Diabetes, Obesity \& Metabolism 11, 913-30.

Pols, J. 2010: The heart of the matter. About good nursing and telecare. Health Care Analysis 18, 374-88.

Ricciardi, L., Mostashari, F., Murphy, J., Daniel, J.G. and Siminerio, E.P. 2013: A national action plan to support consumer engagement via e-health. Health Affairs 32, 376-84.

Stone, R.A., Sevick, M.A., Rao, R.H., Macpherson, D.S., Cheng, C., Kim, S., Hough, L.J. and Derubertis, F.R. 2012: The diabetes telemonitoring study extension: an exploratory randomized comparison of alternative interventions to maintain glycemic control after withdrawal of diabetes home telemonitoring. Journal of the American Medical Informatics Association 19, 973-79.

Takahashi, P.Y., Pecina, J.L., Upatising, B., Chaudhry, R., Shah, N.D., Van Houten, H., Cha, S., Croghan, I., Naessens, J.M. and Hanson, G.J. 2012: A randomized controlled trial of telemonitoring in older adults with multiple health issues to prevent hospitalizations and emergency department visits. Archives of Internal Medicine 172, 773-79.

Wakefield, B.J., Koopman, R.J., Keplinger, L.E., Bomar, M., Bernt, B., Johanning, J.L., Kruse, R.L., Davis, J.W., Wakefield, D.S. and Mehr, D.R. 2014: Effect of home telemonitoring on glycemic and blood pressure control in primary care clinic patients with diabetes. Telemedicine Journal and E-Health 20, 199-205.

Wang, J., Imai, K., Engelgau, M.M., Geiss, L.S., Wen, C. and Zhang, P. 2009: Secular trends in diabetes-related preventable hospitalizations in the United States, 1998-2006. Diabetes Care 32, 1213-217.

Weinstock, R.S., Teresi, J.A., Goland, R., Izquierdo, R., Palmas, W., Eimicke, J.P., Ebner, S., Shea, S. and Consortium, I.D. 2011: Glycemic control and health disparities in older ethnically diverse underserved adults with diabetes: five-year results from the Informatics for Diabetes Education and Telemedicine (IDEATel) study. Diabetes Care 34, 274-79. 